\title{
Towards a typology of electronic product information distribution
}

\author{
M.H. Jansen ${ }^{a}$, B.H.P.J. Vermeer ${ }^{\text {a }}$, H.S. Jagdev ${ }^{b}$ ** \\ ${ }^{\mathrm{a}}$ Graduate School oj Industrial Engineering and Management Science, Eindhoven University of Technology, PAV D-10, P.O. Box 513, \\ NL-5600 MB Eindhoven, Netherlands

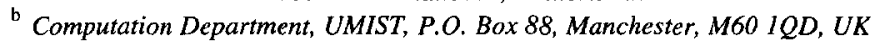

\begin{abstract}
In today's manufacturing business chains organizations have to co-operate to meet the ever changing customer requirements for more specific and more complex products. This results in an enormous increase in the need for product information in the different organizations within the business chain. This need can only be satisfied through switching to electronic distribution of product data in the business chain. In this paper, we consider some approaches to electronic distribution of product information. Although this seems to be a technical problem at first sight, the main issues are caused by the number of parties involved, leading to organizational and political oriented questions. This is illustrated by a number of cases, resulting in a typology for product information distribution. (C) 1997 Elsevier Science B.V.
\end{abstract}

Keywords: Business chains; Extended enterprises; Co-operation in manufacturing; Electronic data interchange

\section{Introduction}

Nowadays, manufacturing business chains have to improve their performance continuously. Customers require more often more specific and more complex products. Companies respond to this by shortening the product life cycles (PLCs) and by returning to their core business [1]. A prerequisite to meet the requirements is to co-operate by using concepts like concurrent engineering, concurrent manufacturing, etc. Co-operation implies an increasing need to exchange product data, to exchange more data, to do it more frequently and faster and between legally independent parties. It turned out that existing means like mail, fax and telephone are inadequate for the required volumes of data which means that one has to resort to electronic means for data exchange.

\footnotetext{
${ }^{*}$ Corresponding author. E-mail: hjagdev@umist.ac.uk.
}

\subsection{Pressures towards large scale data distribution}

In Browne et al. [2], several trends for future manufacturing systems are described: globalized competition, shortened product life cycles (PLCs) and declined added value and reintegration of manufacturing and sales as a result of customer driven manufacturing. Shorter PLCs and increasing numbers of product variants cause that information in product catalogues to become increasingly obsolete. For example, nowadays, it takes the same time (4 years) to develop a product family with 30000 variants as it took 30 years ago to develop only one product. Furthermore, the average number of product variants per product has increased about 300 times in 30 years [3]. This example shows that the growth of frequency and volume of engineering changes results in an increasing need for product information distribution. 
Other reasons for large scale information distribution are due to the changing nature of goods flows, which demand more and more different kinds of information. In the food industry for example, requirements in the field of product quality or liability, environmental friendly production and the like increasingly result in added value. The requested product history data is derived from production processes and production means, and arc impossible or difficult to measure at the product itself [4]. Therefore, these data are derived from the phases a product has passed through: product design, selection of raw materials, production, distribution, use and waste (or recycling). Applications are for example to guarantee the quality of food, as is shown by trade marks like Max Havelaar and quality labels like ISO-9000. Furthermore, products can be recalled from the market (for example cars with a specific engine, in aerospace or defense), and when products are harmful to people (drugs: general law on opiates).

\subsection{Problems with implementing large scale data distribution}

When it is the point to implement the electronic distribution of (product) data, companies tend to address this as a technical problem: "Put the cables in the ground, and let's communicate!' Although this line of reasoning was probably correct for the introduction of the fax machine, this solution is not sufficient for the electronic exchange of data between computer systems. First, a specific business chain consists of many parties, each using different applications based on different systems, different requirements, etc. Since these parties are legally independent, there is no general 'chain management' that can decide on a standardization, which makes their mutual connection extremely difficult. Secondly, the data itself causes difficulties: sending bits and bytes over a communication line does not mean that the connected systems gather the same meaning from the data.

In this paper, a number of cases from industry are elaborated (Section 2). From these cases, typical solutions are described and evaluated. In Section 3, the results are generalized and depicted in a typology of product information distribution problems. We will conclude, in Section 5, that the kind of solution is dependent on the type of product information distribution; however, the existing technical solutions appear to be insufficient and further research is required.

\section{Cases studies}

In our research we have carried out four investigative case-studies to study current industry practice on product data distribution. The focus of these studies was to describe how product information was exchanged, which problems occurred and what the probable causes for these problems were.

\subsection{The electrotechnical case}

\subsubsection{The electrotechnical business chain}

The electrotechnical (ET) sector serves two major markets: the consumer market and the industrial market. For the consumer market, for example, illumination products are manufactured and distributed to the consumers through department stores, supermarkets and specialized illumination stores. In the industrial market, illumination parts are supplied to the building industry, the maintenance market and the governmental market. These markets are characterized by (building) projects. In this paper we will focus on the electrotechnical business chain for the industrial market. This chain consists of two main parts: (a) design and construction and (b) supply. In the first part, principals, their architects, constructors and contractors co-operate with the electrotechnical installation companies in designing and installing the electrotechnical subsystems in the building project. In the supply part, ET manufacturers deliver their products to the installers through the ET wholesalers. The ET supply chain for the industrial market is represented in Fig. 1.

Analogous with the distinction of the two parts in the ET business chain, we distinguish two main flows of product information:

- technical product information, to support the design process;

- commercial product information, to support the ordering process by selection information, logistical product information and price information. 


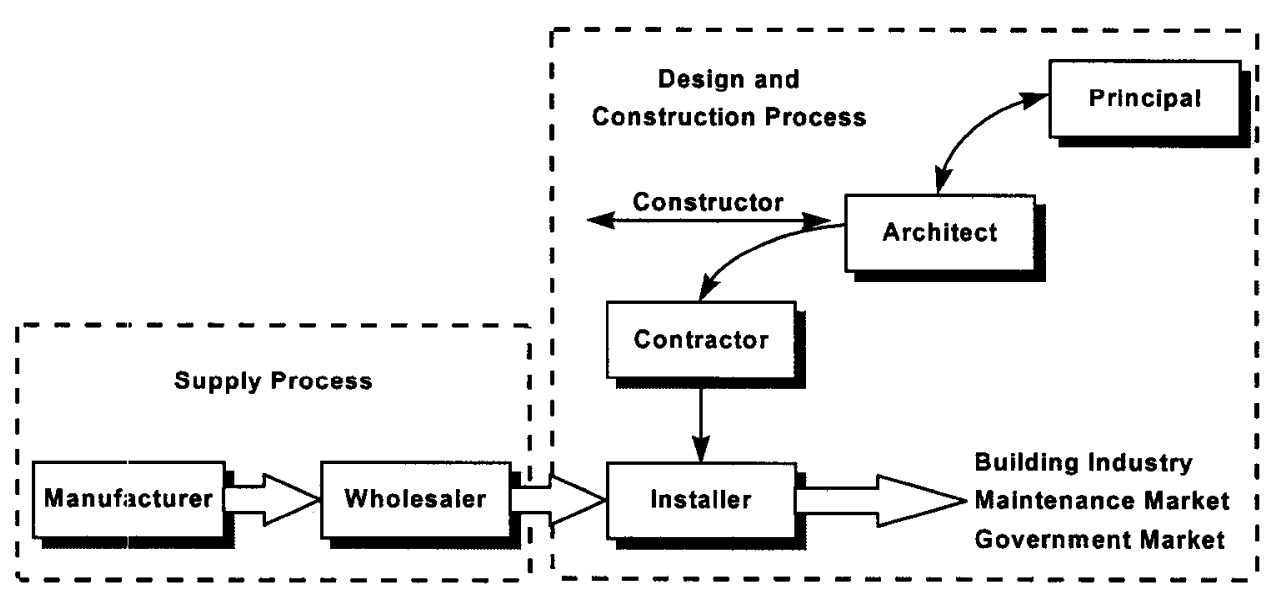

Fig. 1. The ET business chain.

\subsubsection{Case description}

In the ET business chain at the moment two initiatives for electronic information distribution exist:

- Centralized distribution via a sector wide product database;

- Decentralized distribution via electronic data interchange (EDI) article messages.

2.1.2.1. Central product database. In the past few years, the installers representation organization Uneto [5] developed the Electro Technical Information Model (ETIM). This model is a framework that contains a generic description of all business processes of the typical installer. The objective of ETIM was that it was used by software developers as a reference model to guarantee optimal cooperation between the information systems of different installers. One result of this initiative was the development of the ETIM classification structure, which represented a uniform technical classification of all products in the ET sector. The objective of the ETIM

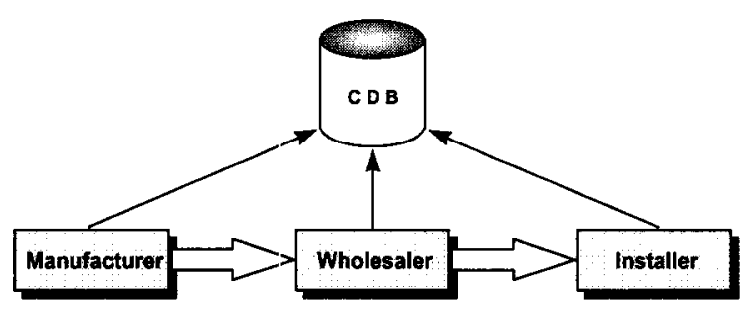

Fig. 2. A central database. classification structure was that it should facilitate product search.

A second result of the ETIM initiative is the Uneto [5] central product database (see Fig. 2). This database is being currently developed and is intended to contain all products in the ET sector. The objective of this database is to offer installers the possibility to search the database for all suppliers that supply products with certain technical specifications. These specifications are based on the ETIM classification. The following advantages are mentioned:

- No re-keying of information.

- Fast search of relevant suppliers.

- Single source for up to date product information.

2.1.2.2. EDI-article messages. Manufacturers and wholesalers in the ET business chain, however, proposed a different solution for the electronic exchange of product information, namely the use of EDI article messages. This means that a certain information supplier sends all relevant product information electronically via an EDI article message to the information customer. Because the message is send via the generic EDI standard format, this should guarantee that the information can be read automatically by the receiving application. Using the EDI article message also avoids re-keying of the information. Furthermore, the EDI article message is very flexible, since the EDI article message is always exchanged between any pair of organizations. This means that for each pair of organizations different implementation agreements can be established. 


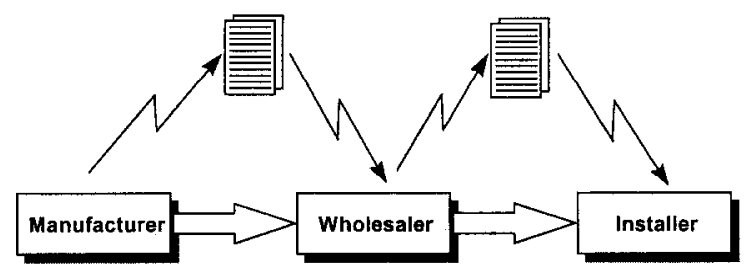

Fig. 3. The EDI article message.

The EDI article message initiative is illustrated by Fig. 3. Since the EDI article message is implemented between each pair of organizations, this method is considered to be decentral.

2.1.2.3. Problems. The main problem in the sector is that both installers and suppliers/wholesalers are arguing that their method should be used for product information distribution. From interviews with participants and related research we found several arguments against both methods.

Manufacturers and wholesalers are strongly opposed to a central database because this implies that installers not only receive (technical) information on their products, but also information on prices and availability of products. They fear that a central database creates a transparent market, where customers determine product choice only through price comparisons. An already existing example of such a situation can be found in the travel sector, where a travel agent can query the database for the cheapest ticket. A second argument is the fact that the information has to be supplied to a third party that is responsible for the collection and distribution of the information. This means that either a new party or an existing party will gain considerable power because it controls the entire flow of information in the business chain. This situation can be compared to a situation where only one television station exists, where everyone has to turn to for advertising. Furthermore, the data in the database contains valuable information such as sales information, price-development information, assortment information, etc. which means that the party that exploits the database becomes an even more powerful player in the business chain. To summarize: The central database initiative means that manufacturers and wholesalers lose control over the product information.
The installers argue that the use of EDI article messages does not guarantee a complete market overview: this overview depends on how many suppliers deliver information to the installers. Furthermore, EDI messages do not guarantee correct information supply. A short field study in the food sector [6] showed that the poor quality of product information resulted from the fact that:

- product and price updates are hardly ever on time, in the right format, or complete;

- organizations are overflowed with product information they do not need.

The use of an EDI article message will not prevent this from happening. This can be compared to the distribution of name address and domicile data (NAD-dala) using business cards. Just as in an EDI article message with a business card a set of standardized data is distributed in a standard format. However, after some time has passed, it almost certainly appears that the information on received business cards is inaccurate because the information has aged. Likewise, it appears that the owner, when updates occur, never knows exactly whom he gave his cards to. To summarize: A standardized format to exchange article data will not prevent the data from being too late, not complete or even completely false.

\subsubsection{Case evaluation}

When we look at the problems with both distribution methods we believe there are three reasons why both distribution methods fail:

1. No distinction is made between the different purposes of using the product information in different processes: The focus of the presented distribution methods is clearly on defining an optimal solution for one flow of product information. However, the commercial use of the product information in the selection process poses other demands on the product information than the use of the information in the design process does. When an installer searches for a product, the supplier wants to be able to present himself as a supplier of the product or even of a range of products. To support this process, the supplier might want to provide his own catalogue that optimally leads to the right product for the right solution. Therefore, product information to sup- 
port this process typically consists of product images, sales information, prices and discounts, etc. On the other hand, the supply of technical design information will normally take place after the product is sold, or at least after the contract is concluded. This means that only known customers will receive this information. However, technical design information typically consists of all kinds of measurements, product drawings, etc. Therefore, product information to support the commercial selection process is different from product information that supports the technical design process. Because both the content and the purpose of the product information is different it is likely that the way the information is distributed is also different. '

2. The supplier has a major interest in what happens with his information: In contrast with the distribution of physical products product information has the same characteristics as personal information. This means that the supplier does not want all customers to have all his information. This explains the resistance of the manufacturers and wholesalers.

3. Technology and functionality are not separated: The presented difference between central distribution via a database and decentral distribution via EDI messages makes an unnecessary coupling between the technology of interchange and the desired functionality of a product information distribution system. With central distribution in fact central access to information is meant and with decentral distribution the fact that only two parties have access to information. However, between these extremes in access many hybrid situations are possible (like limited access for certain groups). The discussion on a product information distribution system should focus on defining the precise functionality. Next to access, also other issues should be involved in this discussion such as security, availability, etc. The implementation of these functicnalities in a technical distribution system is from a different order. As an example:

\footnotetext{
'Compare this with physical products: the distribution system for cars is also likely tio be different from the distribution system for diamonds.
}

most EDI messaging systems are from a technical point of view central databases with mailboxcs for each customer that are administered by a value added network provider (VAN). However, the functionality of these systems is perceived as being a decentral system.

\subsection{The food distribution case}

\subsubsection{Case description}

With the implementation of scanning and FDI in the fast moving consumer goods sector in the beginning of the $80 \mathrm{~s}$, both manufacturers and retailers made an agreement: In exchange for putting bar codes and identification numbers on their products, the manufaccurers would receive point of sales (POS) information from the retailers. Point of sales information stands for information about the number of sold products that are scanned at the check-out in the supermarket. This is valuable information for manufacturers that they can use in their logistical and marketing processes.

To accomplish this a project was started to implement the exchange of POS data. In the project it was decided to develop a central database where the manufacturers would deliver article data and where retailers would add the POS data per article. The database itself was housed at a neutral party. The intention of having manufacturers to deliver their article data was to kill two birds with one stone: when manufacturers deliver article data themselves it is guaranteed that the database contains up to date product numbers. Furthermore, when extra product information was attached, the database was a perfect resource for retailers to update their product master files. The product information interchange proposed in this project is illustrated in Fig. 4.

However, in 1988 the project was abandoned because of lack of interest. Manufacturers were not interested in the POS information because they already bought their market information at the market research agencies. The most important reason for them to buy this information is that the POS information itself is nothing more than some kind of a half-product that still has to be finished. Market agencies claim they can do that cheaper, because they have economies of scale. Furthermore, the proposed database requested manufacturers to supply all 


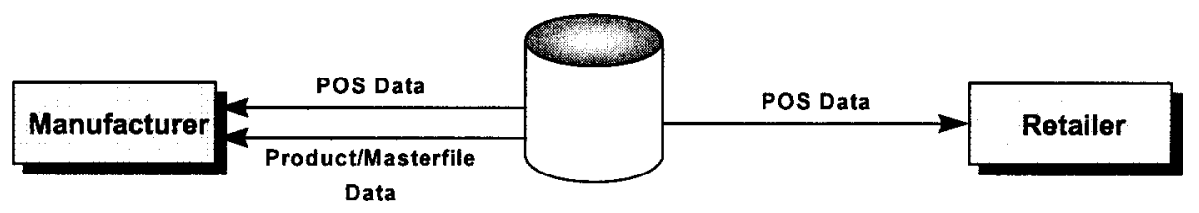

Fig. 4. Product information interchange in the food chain.

their article information to the database; something not all manufacturers were willing to do. Also, the market agencies were not interested, because they invested large funds in their own databases. Finally, the retailers were not interested, because the market information in the database was intended for manufacturers, not for retailers.

Because of the failure of the system both manufacturers and retailers recently started a new initiative to investigate the possibilities of implementing an electronic distribution system for basic product information ( $=$ product/masterfile data) to synchronize basic product information in the business chain. This is necessary because subsequent organizations in the business chain do not have identical basic product information. This leads to a situation that the computer system of one organization 'thinks' it orders a pallet of chocolate milk whilc the other computer system 'thinks' it received an order for just one packet of the product. However, compared with other countries this initiative is 2 years late.

\subsubsection{Case evaluation}

In the project a central database is proposed and a solution to the POD distribution problem. When we look closely at the project we see that not one but in fact two separate information flows can be distinguished:

1. The POS information flow from retailers to manufacturers.

2. The product/masterfile data flow from manufacturer to retailer.

From the project description it is clear that the POS information flow was not a success because the provided information was not what the manufacturers wanted. However, because the project was abandoned, also the basic product information (product masterfile data) interchange was abandoned. It is clear that this particular application finally appeared to be very useful. Therefore it is concluded that the fact that no distinction was made between two differ- ent information flows in the project, shows that this was an important reason for the project's failing.

\subsection{The pharma case}

\subsubsection{Case description}

2.3.1.1. Productview. In 1993 three suppliers of medical convenience goods and three hospitals started the Productview project. The initial objective of Productview was to provide a single uniform product catalogue to hospital purchasers in an electronic form. That would enable purchasers to select products from suppliers quickly and easily. Furthermore, logistical and technical data would be immediately available. This was important because product data was becoming increasingly obsolete.

Productview was set up as a central database where supplicrs send information about their assortments and the properties of their products and where hospitals receive all this information on a local PC. The product distribution process is illustrated in Fig. 5.

\subsubsection{Advantages and disadvantages. A number of} advantages were mentioned in the Productview initiative. Advantages for suppliers are:

- The possibilities of cutting costs in catalogue production. These costs are huge (min. fl. 100.000) and increasing through an increasing amount of product changes and new products.

- Fewer questions at the customer service department.

- Standard source of information, also for internal use.

The hospitals benefit by having one source of information that is always up to date and which contains the latest information on new products.

2.3.1.3. Problems. In the beginning the Productview initiative encountered resistance from manufacturers and wholesalers. The pharmaceutical wholesaler, for 


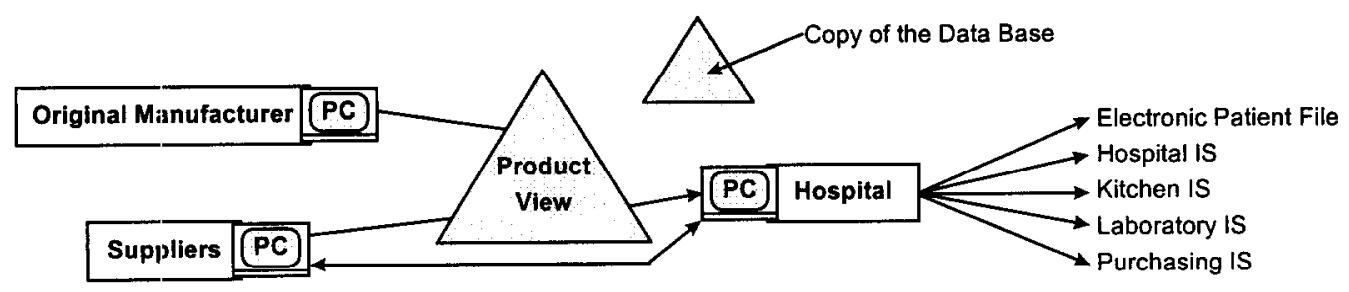

Fig. 5. Product information distribution via Productview.

instance, argued that they do not sell individual products but services on product packages, which are tuned to their individual customers. Providing product information to hospitals about individual products therefore does not meet the commercial strategy of the pharmaceutical wholesaler.

In 1994 the database was handed over to an already existing neutral organization in the health care sector (the SIG). At that moment it was decided to concentrate on the logistical and technical product information and to let price and availability information rest (commercial information). At the end of 1995 almost 40 suppliers and 20 hospitals are participating, who exchange information about $50 \%$ of the total product assortment of medical convenience goods.

\subsubsection{Case evaluation}

The main reason for the initial problems in the Productview project was that one had adopted the old concept of the paper catalogue simply in an electronic counterpart. However, a catalogue provides many different functions, where the most important distinction is the difference between the look, choose and buy function and the synchronization of technical and logistical data between different organizations. In the look, choose and buy function, a person is the spill of the system. Therefore, manufacturers and wholesalers want to have the ability to present themselves as well as possible. In the synchronization function the computer is the spill of the system: The logistical proccss of scanning, automatic generation of stock replenishment orders, sending of orders via EDI, etc. will fail the moment the product information at the different organizations in the supply chain is not exactly the same. Because this distinction did not exist, there was also no difference in the way the information to support these completely different processes was provided. From the case it is clear that the look, choose and buy function will require different support with product information than the synchronization function.

\subsection{The food processing industry case}

In the food industry, product quality and the associated responsibility are key factors for successful business. The food sector can be characterized by complex supply chains and therefore, product quality and responsibility are common problems that require joint initiatives, as can be seen in the following example.

\subsubsection{Case description}

A manufacturer of baby food produces small pots of minced meat, vegetables and potatoes. The production process is very well controlled, all batches can be identified and all production data that are related to the batches are recorded and are traceable. Furthermore, this manufacturer requests that the quality of supplied products is guaranteed and that the suppliers are ISO-9000 certified. One day, however, one of the sold pots appeared to be tainted. The manufacturer faced the following two problems: firstly, what caused the decay and who is responsible and, secondly, which sold pots are tainted and who bought these.

Analysis of the food proved that the taint was caused by the meat. Thanks to the tracing system, the supplier was located and further analysis revealed that a kind of detergent was added to the meat. The supplier had subcontracted a (ISO-9000 certified) cleaning firm that had used more detergent than required, causing machines to leave detergent residue on the dishes. This situation is depicted in Fig. 6.

The manufacturer was able to identify all batches in which the tainted meat was used. Howcver, they 
did not know who bought those pots and they were not able to recall the products from the market effectively. In the end they had to recall all products of the tainted type that were in the market, and additionally due to a negative influence from the tainted product, the time spent to recall it and the mistakes made they even had to recall other types of their baby food.

\subsubsection{Case evaluation}

This case explains that well organized internal logistics and registration are not sufficient in supply chains in which the parties are highly mutually dependent. The manufacturer thought that they could not make a mistake in their production process and that their suppliers can be held responsible for their own faults. Apart from the fact that this appeared not to be true, the brand name sustained considerable damage.

The damage could have been reduced greatly if they had known their customers, and others, in the supply chain. This requires tracking and tracing facilities, in addition to the ones internally implemented. Tracing was implemented by adding an individual batch product code to the products and cross-refer encing them to all associated raw materials.

Tracking, however, requests more information handling and more costs, which was the reason why this part of the system was not implemented by the baby food manufacturer. The objective of a tracking registration system is that the manufacturer acquires control over the supply chain, from direct customer up to the last selling point. Only through using detailed tracking systems in the entire supply chain it is possible to recover product history information immediately thus enabling a fast and detailed product recall. In general, it is concluded that a theory on the exchange of product history data is necessary.

From the above it is clear that two extreme situations exist:

1. Store all product data about what went into the product, when it was manufactured, when it was shipped etc. at the source and recover the history of a product through tracing back in the chain.

2. Pro-actively distribute this product data through the supply chain, thereby providing immediate access to the history of the product.

Somewhere there is a balance between the costs of pro-actively distributing the product history data and the costs of a total product recall. The longer the history of a product is, the more difficult it is to recover that history through tracing, and therefore the higher the risk of a total recall and the associating costs are. On the other hand, when the product history is short, the recovery of the history is simple and therefore the costs for pro-actively distributing the history for all products are relatively high. Since the product history increases going from the manufacturer to the consumer in the supply chain, somewhere there should be a point of balance. We will refer to this point as an information decoupling point (IDP). The IDP is a variant of the customer order decoupling point (CODP) known from logistics: it identifies the point in the production chain up to where the costs for tracing are lower than the costs for implementing a tracking system. From this point on the costs for pro-actively distributing the information (a tracking system) are lower.

A number of cases that can be compared with the baby food case can be described here. Amongst others the cattle and beef production in Europe was paralysed by mad-cow-disease in the UK, cats were

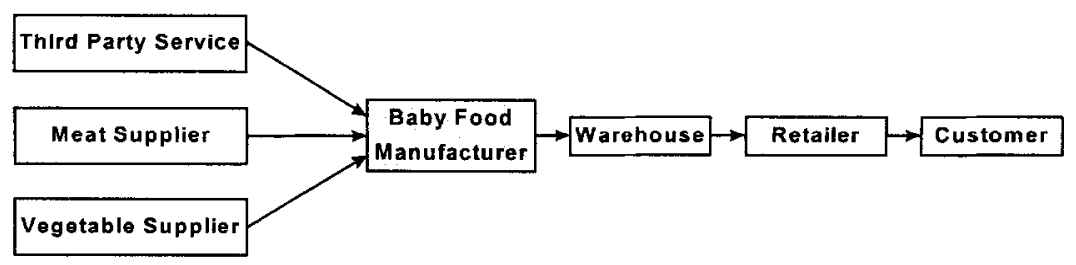

Tracing (Back) from Manufacturer(s) Tracking (Forward) from Manufacturer(s)

Fig. 6. Food processing-situation overview. 
paralysed by a specific type of fodder, deep-frozen vegetables were mixed with glass, etc. In general, those cases have in common that the pro-active exchange of product data is scarce. The manufacturer balances his risks and costs, neglecting the fact that it is hard to quantify both variables. Mad-cow-disease, for example, caused a $20 \%$ decrease of beef consumption in the EC no matter whether the cattle was influenced with BSE (which was unknown in the UK) or even whether they came from Poland or Greece.

Another conclusion that can be drawn is the difficulty of defining the information decoupling point: how much information should be kept at source, how much should be accessible through identification and linking and how much should be spread with the product. The baby food case showed that a fully decentralized approach, however low-priced during implementation, appeared to be very expensive in the long run.

\subsection{The plastics manufacturing case}

Although this example looks very different from the previous cases, it highlights similar problems and raises identical technical issues of data transfer between the organizations of business chains, as discussed in the previcus cases.

\subsubsection{Case description}

Because of the inherent and recognized benefits, therc has been an explosive growth in the use of plastic parts. Many parts which usually were made of metals are now made of plastics. Indeed, plastic components can be found in all walks life ranging from the aerospace industry to the automobile industry, electronics industry and through to the consumer durables and consumables. Plastic parts now can be made in very complex designs, precise and close tolerances, range of surface finishes and, most importantly, a wide variety of plastic raw materials giving the user precise qualities in terms of strength, ductility, re-usability, useful life span of the parts and the cost of parts. Hence the benefits of replacing metal alloys with plastics are clear and unambiguous.

The process of design, development, engineering and production of new plastic parts involves partnership and constant interaction between several enter-

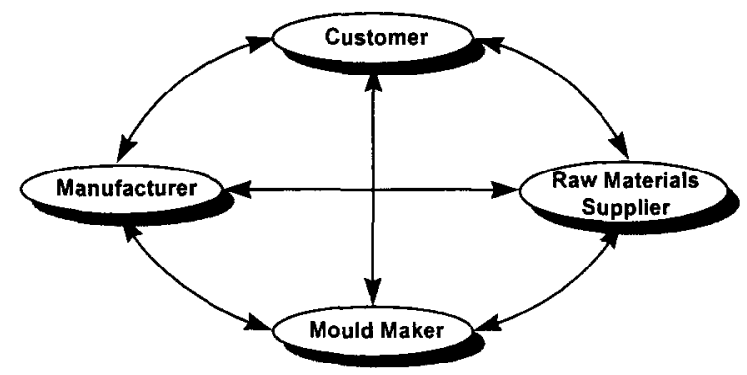

Fig. 7. Traditional relationship among key players in the manufacture of plastics parts.

prises throughout the lifetime of the order. This operating environment is unique and more complex than traditional manufacturing systems where much of the design is done within a single enterprise; the key players being the customer, the plastics parts manufacturer, the mould maker and the raw materials supplier. The traditional interrelationship among these key players, depicted in Fig. 7, has been rather haphazard.

The customer is a manufacturer who uses the plastic components in his products. He can go to the manufacturer with detailed designs and specifications and expect from him to get the moulds manufactured and confirm the delivery dates and costs. $\mathrm{He}$ could go to the mould maker with part designs, get the moulds manufactured and then go to the manufacturer with the delivery and costs quotations. The customer could also interact with the raw materials supplier with respect to the properties of various plastics and possibilities of using a certain percentage of some specific re-cycled materials.

Manufacturers of plastic components, usually, have sophisticated moulding machines (usually injection) and special test equipment. This type of set-up gives them large flexibility with respect to the variety and the number of products that they can manufacture. Their interaction with the customers involves getting the orders and supplying the parts at the agreed time schedules and costs. Manufacturers have to talk to the mould makers with respect to design/re-design of the moulds. The manufacturer interacts with the raw materials supplier with respect to the properties of various plastics and possibilities of using a certain percentage of some specific recycled materials. 


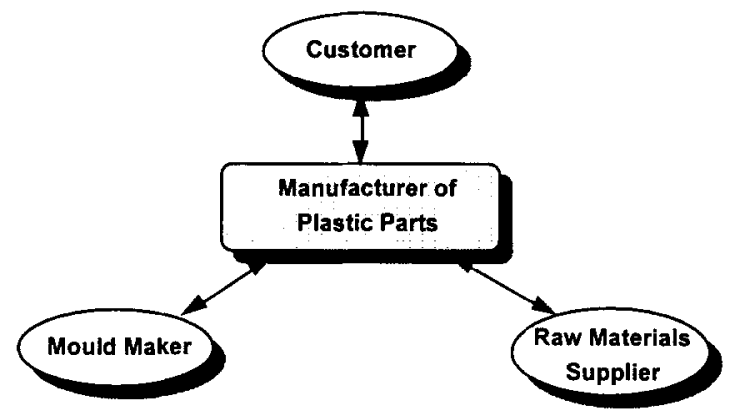

Fig. 8. Extended enterprise view of the manufacture of plastic parts.

The mould making enterprise is a typical engineer to order (ETO) jobbing shop. They employ a very highly skilled work force operating some of the latest machine tools. The mould maker interacts with the customer with respect to the mould design, delivery times and costs. Its interaction with the manufacturer will include technical enhancements of moulds, delivery schedules and the costs. With the raw materials supplier the discussions will mainly be of a technical nature with respect to the behaviour of various plastics during the manufacturing process such as the flow behaviour, cooling behaviour, stress behaviour, etc.

Due to increasing competition and the associated cost, delivery, quality and reliability constraints have forced manufacturers to streamline the information exchange among the key players, resulting in the evolution of plastics inter-enterprise topology shown in Fig. 8. This inter-relationship takes full advantage of the emerging technologies (communications, hardware) and manufacturing philosophies (just-in-time, market pull systems) into a viable 'extended enterprise'.

Here the manufacturer of the plastic parts is at the hub of the extended enterprise. It supplies to the customers not only the plastic parts but a conplete service related to the manufacturing and design solutions and their respective cost aspects. It interacts with other satellite enterprises regarding all design, cost and schedule issues. Improved communications are achieved via EDI connecting seamlessly the information systems of all the satellite enterprises to that of the hub. Fig. 9 outlines the basic EDI structure and its interfacing within the extended enterprise. This interfacing is done via special decision support systems (DSS) which contain algorithms to sort the incoming and outgoing data, associate priorities to them and pass them onto the correct destination be it another computer or a human. They also contain special tuneable filters to prevent sensitive information going out. A discussion on the detailed structure of these DSSs and the connecting of the EDI bus is beyond the scope of this paper.

\subsubsection{Case evaluation}

As described in the previous section, there are three links in this business chain as depicted in Fig.

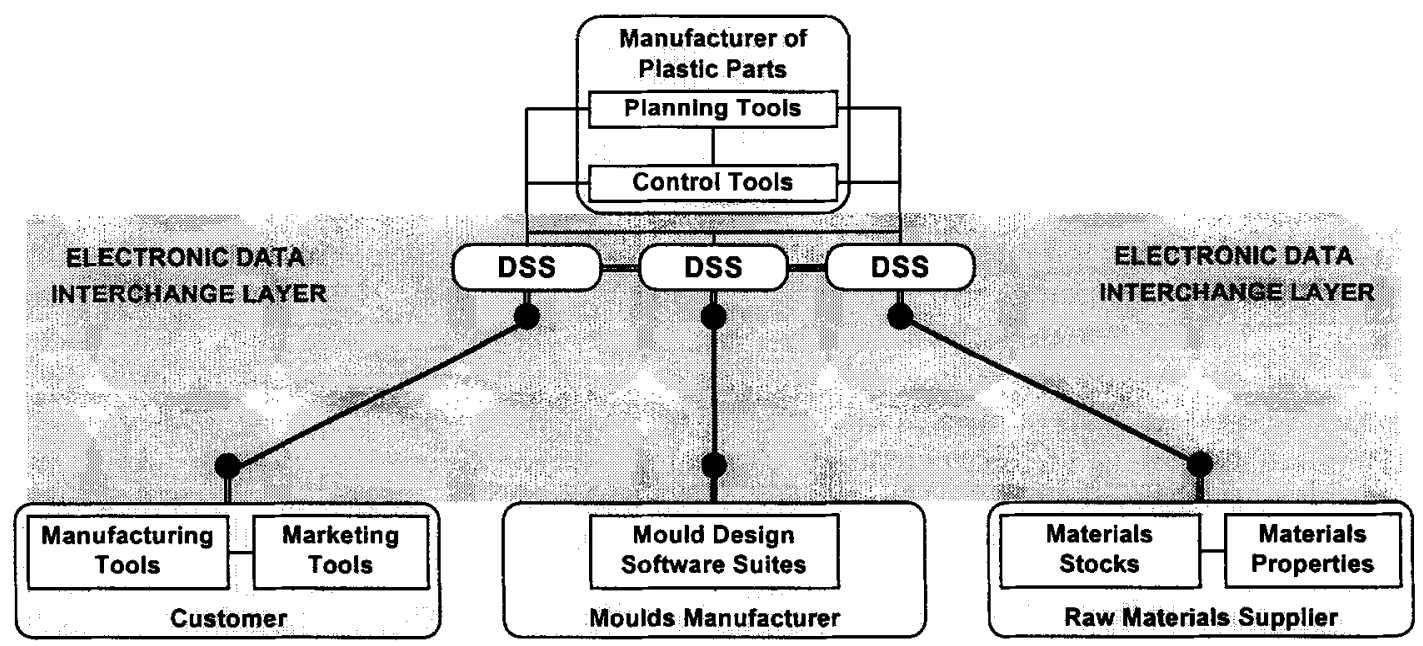

Fig. 9. EDI interfacing within the plastic parts manufacturing extended enterprise. 
9. Within each EDI link there is a unique set of data structures that need to be exchanged. The following paragraphs briefly describe the types of data. The issues related to the data visibility and exchange are very similar to the ones described in Sections 2.1.3, 2.2.2, 2.3.2 and 2.4.2.

\subsubsection{Data exchange between the plastics manu-} facturer and the customer. Here the issues are related to the exchange of documents which are related, directly or indirectly, to the order processing flow. This includes:

- Logistics: order variations, order confirmations, dispatch advises, call-offs, just-in-time messages, delivery schedules and dates, etc.

- Technical: part drawings, technical specifications of the finished parts (finish quality, strength requirements), design issues and proposed variations to the designs, raw material specifications and possible alternative advises, etc.

- Financial: price expectations, quotations, invoices, dispatch advises, debit advises, credit advises, etc.

- Other: catalogues, lists, etc.

\subsubsection{Data exchange between the plastics manu-} facturer and the mould maker. For a given finished part, the corresponding mould can be designed in more than one way. The way the mould is designed reflects on the production rates once the mould is in operation. Most of these mould performance issues can only be captured by the parts manufacturer. Hence there is a strong need for the feedback to the mould maker so that the moulds are made to the right design specifications and also there is a possibility of continuously and quickly improving them, once any shortcomings are noticed. Other specific issues include:

- Logistics: order confirmations, call-offs, just-intime messages, delivery constraints, schedules and dates, manufacturing constraints, etc.

- Technical: part geometry and drawings (2D and 3D between sarne and different CAD systems), mould designs, mould behaviour and performance, technical specifications of the finished parts (finish quality, strength requirements), design issues and proposed variations to the designs, raw material specifications and possible alternative advises, etc.

- Financial: price expectations, quotations, invoices, dispatch advises, debit advises, credit advises, etc.

- Other: catalogues, lists, etc. related to both raw materials and the mould designs.

\subsubsection{Data exchange between the plastics manu-} facturer and the materials supplier. The link between the raw materials suppliers and other enterprises may seem to be innocuous one-at present. However, as new materials are being developed, it is important that their specifications and properties become known to the prospective suppliers quickly. Hence as the moulds for the components are being designed, new materials and their mechanical and physical properties have to be taken into account for the optimal design and minimal rejection rates during the manufacturing of the components (see also Section 2.3.2). Moreover, as the environmental requirements impose more recycling of plastics, these communication lines will become as important and relevant as the other links. Then the selection and proportions of used and virgin plastics will play an important role in the manufacturing cycle. This will encourage the manufacturers to consider those virgin materials that can accommodate more proportions of the used plastics without compromising the required properties of the finished parts.

2.5.2.4. Manufacturing control issues. To take the real advantages of this extended enterprise the plastics manufacturer has to integrate respective decision support modules (three DSSs depicted in Fig. 9) seamlessly with its own manufacturing planning and control system. The issue here is very simple one: no matter how effectively a particular resource is scheduled and managed, it cannot be considered on its own. Constraints on other resources may invalidate the most efficient individual resource schedule, seen from the viewpoint of delivering the complicated product to the customer. To improve its competitiveness, the plastics manufacturer must incorporate the concepts of concurrent planning and constraint based planning to make the manufacturing chain operate to just-in-time principles. 
To incorporate constraint based planning techniques means that all the resources and materials needed to deliver the product have to be delivered and assembled at the latest possible moment. They will have to integrate their operations with that of customers and the mould makers to extend the individual islands of automation and incorporate the pulling of materials (both raw materials and the moulds) so as to use the just-in-time techniques. The decision support system overseeing these aspects must monitor and report the critical bottlenecks-not as they happen but, most importantly, before they become critical. An integrated concurrent planning approach can be seen as the 'foundation' system needed to combine today's separate functional plans into one overall plan. It is the means by which the resource supply and demand data (usually stored on a variety of media including computer files, paper documents and individual knowledge), can be combined into a total picture of the enterprise.

In addition to the job of gathering this data, and ensuring that it is complete, an integrated to concurrent planning approach will also help to introduce new business practices, such as constraint optimization, within a planning management system. Its final goal is to provide the effective overall control system, driven by profit considerations, which is essential for the future competitiveness. It must be seen to present added value to the business from the viewpoint of individual functions, individual enterprises within the chain and the whole integrated chain itself. If successfully implemented such methodology will improve the data management and create wider operational visibility to help integrate strategic, tactical planning and control activities resulting in the increased throughput and the net income for all the co-operating enterprises.

\section{Towards a typology of product information distribution}

The previous cases clearly illustrate that the electronic distribution of product information poses serious problems for organizations in practice. For these organizations it is important to understand why these specific problems occur. Insight into the difference between the distribution situations presented in the five cases and their characteristics may provide this understanding.

Looking at the presented cases it is possible to make a distinction between the first three cases and the last case. In the first three cases the product information involved is about commercial (catalogue), technical and logistical information of a more general product. In the last case the product information is concerned with historic information and status information about a specific product. We believe that the described different product information distribution situations in the first three cases compared with the last one are a result of the difference between the structure and the behaviour of a system and the resulting information flows following from this difference.

\section{Structure vs behaviour}

In the description of systems (both business and information systems) Hofman [7,8] makes an explicit distinction between the structure and the behaviour of a system. The structure of a system is the static part of that system and the behaviour is the dynamic part. For instance, when studying a distribution system the structure describes for instance that a superior gives instructions to several subordinates to move objects from one place to the other. The behaviour of that system describes then that the liner agent Nedloyd orders stevedore de Vries to load container L1245 on ship 'Mary blue' that ships the container to England, where stevedore Smith is ordered to unload the container. This example of the difference between structure and behaviour is illustrated in Fig. 10.

As we can see from this example, the structure of the system defines the system in generic terms. The behaviour of the system defines a specific, demonstrable shipment, existing in the real world.

The distinction between structure and behaviour of a system implicitly exists in several other concepts:

- In the concepts of object modelling [9] a difference is made between classes and instances. A class describes an object and its properties in general. An instance is a specific occurrence of a class object. The description of the structure of a 


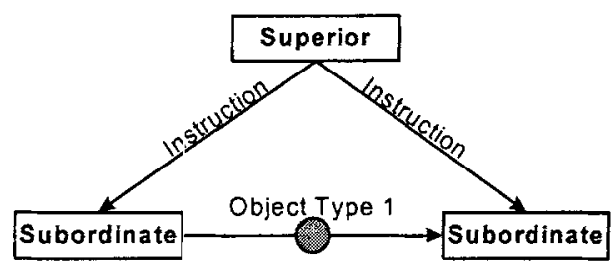

Object Type 2

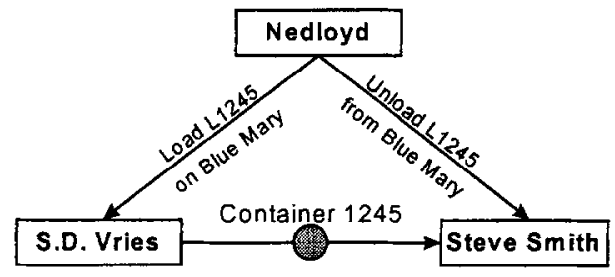

Ship Blue Mary

Fig. 10. Example of difference between structure and behaviour.

system can be viewed as a class definition of that system. The behaviour of the system is then an instantiation of a system object.

- In his concept of the architecture of software for production/inventory control systems Bertrand et al. [10] make a distinction between state-dependent and state-independent transaction processing. State-independent transaction processing systems constitute all kinds of recording of products, technology, manufacturing equipment and personnel, which is indirectly supportive to the recording and planning of orders and materials. State-dependent transaction processing systems monitor the state-transitions of the materials and orders. State-independent transaction processing systems can be viewed as systems that record the structure of the production and distribution process, while state-dependent processing systems record the behaviour of production and distribution process.

- Vermeer [11] defines the difference between object communication and transaction communication to explain problems in product information distribution. Transaction communication is defined as all direct communication between business processes to conclude transactions. Examples are orders and in voices. Object communication is defined as the direct exchange of object information between the database systems of different business processes, which is supportive to transaction communication. Object information refers to all information about objects, such as persons, products, etc. Transaction communication is part of the behaviour of the total business system. Object communication can be viewed as the communication about (changes in) the structure of the business process between different organizations in the business system.

Both the structure and the behaviour of a certain business system lead to different product information distribution situations. Due to structural changes, generic product information is distributed to many different users that can be used for many different purposes. This may lead to political problems as is described in the first three cases. This is very different from the distribution of status information of products in a business chain that results from the registration of behavioural information of specific products in a certain business process. We will refer to the first type as product structure information and the second type as product behavioural information or status information.

\subsection{Characteristics per situation}

Both the distribution situations of product structure and product behaviour information have different characteristics. The most important differences per situation are:

- Product type vs individual product: Product structure information relates to product types and product behaviour information relates to individual products.

- Many different purposes of use vs one single purpose: The distribution situation of product structure information is hampered because the information can be used for many different purposes in many different business processes. In contrast, the purpose of the distribution of product behaviour information is always quite clear.

- Multilateral vs bilateral communication: Product structure information is distributed to many dif- 

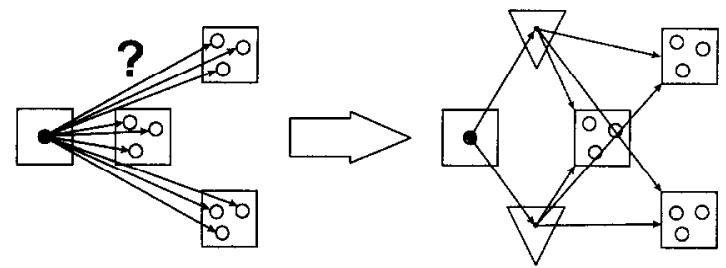

Fig. 11. Objective of product structure information distribution.

ferent parties that are potential users of the information. Product behaviour information is only distributed (when it is needed) to the parties that sequentially buy the product in the business chain.

- Low mutation frequency vs very high mutation frequency: The frequency of changes in product structure information is much lower than the frequency of the generation of product behaviour information. This normally results in a higher communication frequency of product behaviour information compared with product structure information.

- High observation frequency vs low observation frequency: The reverse is the case with the observation frequency. Product structure information is used in many different business processes that frequently refer to structural information about a product. In contrast, product behaviour information is often only used when something in the normal business process goes wrong.

\subsection{Objective per situation}

Because of the different characteristics of each type of product information distribution situation the distribution problem at hand also differs per situation. This results in a different objective per situation.

In the first three cases that deal with structural product information distribution the problem is that there are many different information customers, each with several business processes that require different aspects of the same product information. The main issue is to identify which possible information flows exist. The objective of the distribution situation with product structure information is to design a multiple flow system that combines each of these possible information flows in a coherent information distribution system. This situation is illustrated in Fig. 11.

In the last case that deals with the distribution of product behaviour information, the problem is that status information on products is not distributed at all. However, since the consequences of not having this information are serious, the question is whether to distribute status information or to let it rest at the different parties in the supply chain. Therefore, the main issue is to determine where the information decoupling point (IDP) should be located in the business chain. The objective of this distribution situation is to optimize the costs of recovering from failures versus the costs of distributing status infor-

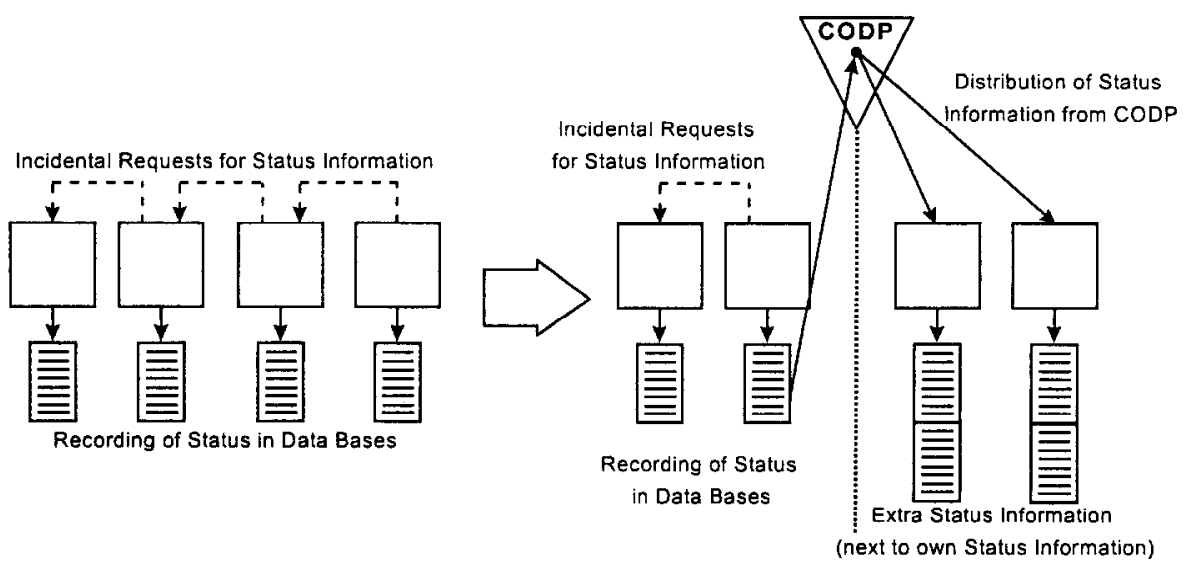

Fig. 12. Objective of product behaviour information distribution. 


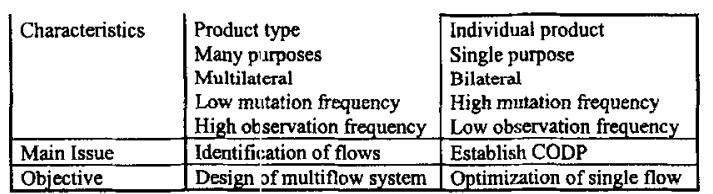

Fig. 13. Typology of product information distribution situations.

mation in a single product information flow. This situation is illustrated in Fig. 12.

\subsection{Typology of product information distribution situations}

Based on the considerations in the former paragraphs a typology of product information distribution situations can be formed as is illustrated in Fig. 13.

\section{Conclusions}

In this paper we discussed four cases describing the specific product information distribution situation and the problems that were found in each situation. The studies show that different situations can be distinguished requiring different solutions.

The main conclusion following from this paper is that the difference between the structure and the behaviour of systems and the two types of distribution situations that result from this difference explain the nature of the problems in the first three cases compared with the last case we studied. Changes in the structure of a system result in the distribution of product information about product types such as catalogue information, technical information or logistical information. In contrast, the systems behaviour is recorded resulting in the recording of product status information. The need for status information to be able to quickly react to unexpected events results in the distribution of product information about individual products. The distribution of product structure information is characterized by many information customers, each with several business processes requiring product information as can be seen from the first three cases. 'To avoid political problems this type of distribution situation therefore has to focus on the identification of product information flows and the bundling of these flows in a coherent distribution system.
The distribution of product behaviour information (status information) is characterized by a high mutation frequency of information that can (potentially) be distributed between partners in a single business chain. This situation was found in the last case. To optimize the costs of recovering from failures versus the costs of distributing status information in a single product information flow this type of distribution situation has to focus on the question of where to place the information decoupling point.

Further research concentrates on defining solutions for each type of product information distribution situation. In 1996 a strategic research programme has been started that focuses on diagnosing and redesigning two business chains by 15 students during 9 months. Special attention will be paid to the identification and redesign of product structure information flows. Also the need for tracking and tracing will be analysed, using the information decoupling point concept.

\section{References}

[1] J.W.M. Bertrand, J.C. Wortmann, J. Wijngaard, Production Control and Material Management, Stenfert Kroese, Leiden, 1990.

[2] J. Browne, P.J. Sacket, J.C. Wortmann, Future manufacturing systems - towards the extended enterprise, Computers in Industry 25 (3) (1995) 235-254.

[3] B.J. Pine, Mass Customization; The New Frontier in Business Competition, Harvard Business School Press, MA, 1993.

[4] M.H. Jansen, IT enabled supply chain management; towards tracking and tracing in agro-industry, in: Proceedings of the Edispuut Conference, 1995.

[5] Uneto, Central Product Database for the ET Sector (in Dutch), Uneto, 1994.

[6] B.H.P.J. Vermeer, Products Are Not Alike! - An Analysis of the Problems of Non-Attuned Product Databases in the Fast Moving Consumer Goods Sector (in Dutch), TU Eindhoven, 1995.

[7] W.J. Hofman, EDI Handbook, Electronic Data Exchange Between Organizations, Tutein Nolthenius, Amsterdam, 1989.

[8] W.J. Hotman, A Conceptual Model of a Business Transaction Management System, Tutein Nolthenius, Den Bosch, The Netherlands, 1994.

[9] D.A. Taylor, Object-Oriented Technology, Kluwer, 1991.

[10] J.W.M. Bertrand, J.C. Wortmann, J. Wijngaard, Production Control: A Structural and Design Oriented Approach, Elsevier, 1990.

[11] B.H.P.J. Vermeer, EDI: electronic distribution of information products, in: Proceedings of the Edispuut Conference, 1995. 